\title{
Usability of Histological Assessment of Cerebellar Granule Cell Layer Regardless of Postmortem Interval
}

\author{
Satomu Morita*, Satoshi Furukawa, Akari Takaya, Ikuo Sakagushi, Hayato Okunaga, Tokiko Nakagawa, Lisa Wingenfeld and Katsuji Nishi
}

Department of Legal Medicine, Shiga University of Medical Science, Japan

\begin{abstract}
We often encounter many decomposed cases in the forensic science fields. Damage to organs by bacteria complicates our diagnosis, examination and study. The central nerve system is one of the most hardly decomposed organs. The cerebellar granule cell layer (GCL) is useful for some investigation.

We histologically evaluated cerebellar GCL of decomposed and fresh cases using Photoshop ${ }^{\mathrm{TM}}$ application. No statistical difference was found between two groups. In addition, we grouped by agonal situation and histologically evaluated cerebellar GCL. We could only show the statistical difference between carbon monoxide (CO) poisoning and house fire because of shortage number of some groups, but the comparison of the box plots suggested some relations between $\mathrm{GCL}$ and agonal situation.
\end{abstract}

We suggest conservation of histological findings of cerebellar GCL regardless of postmortem interval and usability for detecting agonal situation.

Keywords: Cerebellar granule cell layer; Decomposition; Photo shop; Agonal situation; CO poisoning

\section{Introduction}

In the forensic science fields, we encounter many decomposed cases. Damage to organs by bacteria complicates diagnosis, examination and study. Decomposition by bacteria often begins colon, lung and mucous membrane of face that have bacterial flora, next widely spread to whole body in few days. The almost cardinal organs exist in cavity of chest and abdomen that are vulnerable to bacterial invasion. Central nerve system (CNS) is immersed in cerebrospinal fluid that is clearly aseptic except for meningitis cases, and there is no connection to chest and abdominal cavity. According to the report by Stan et al. [1] postmortem interval (PMI) range of 6 to 40 hours does not correlate with the RNA quality in brain [1]. Therefore, we can say that CNS is one of the most hardly decomposed organs.

Cerebellar granule cell layer (GCL) is very useful for some investigations. GCL is noticed for showing unusual change after ischemia like CA1 and CA4 regions of hippocampus in the forensic science [2,3], and showing many neuronal death mechanisms especially for apoptosis in the neurology [4]. And Stan et al. suggested the proportional connection between histological findings of cerebellar GCL and RNA quality [1].

We histologically evaluated GCL in decomposed cases PMI over 40h and quantified with Adobe Photoshop ${ }^{\mathrm{Tm}}$. We also evaluated GCL in some cases, which were dead in different agonal situation, carbon monoxide (CO) poisoning, house fire and suicide by fire.

\section{Materials and Methods}

We chose all decomposed cases that died suddenly from 2009 through 2012; these were 12 cases (Table 1a). Moreover, more we chose fresh 12 cases that also died suddenly in 2012. The causes of death are hanging, drowning, choking, fatal acute myocardial infarction and brain contusion. It must be quite short time from outbreak to death in every case because there was no struggle appearance. We excluded murdered cases because it might not be quite short time to death. Due to bacterial damage, we could not evaluate any GCL of decomposed cases that died for brain contusion. The all autopsy of fresh cases started within $40 \mathrm{~h}$ after death (Table $1 \mathrm{~b}$ ).

During 2012, we conducted surveys of five CO poisoning cases, three victims for house fire and two suicide cases by fire. All CO poisoning cases was suicide-using charcol, which is noticed one of the most famous suicide technique in Japan. From January to March in 2013, we treated four more CO poisoning cases. We excised brain from all the cases, and evaluated GCL.

\begin{tabular}{|c|c|c|c|c|c|c|}
\hline No. & Sex & Age & Cause of death & PMI & Percentage & Pixcel \\
\hline 910 & M & 36 & drowning & 5days & 44.8 & 146728 \\
\hline 912 & M & 34 & drowning & 6days & 44.1 & 144521 \\
\hline 923 & M & 48 & drowning & 12days & 34.1 & 111663 \\
\hline 983 & $\mathrm{~F}$ & 62 & hanging & 7days & 38.0 & 124484 \\
\hline 984 & M & 66 & hanging & 7days & 37.0 & 121165 \\
\hline 1011 & M & 40 & drowning & 20days & 43.3 & 142021 \\
\hline 1024 & M & 53 & drowning & 21days & 33.2 & 108673 \\
\hline 1103 & M & 55 & drowning & 5days & 45.7 & 149800 \\
\hline 1124 & M & 77 & AMI & 14days & 37.4 & 122405 \\
\hline 1169 & M & 78 & AMI & 18days & 54.1 & 177262 \\
\hline 1248 & M & $70^{\star}$ & drowning & 4days & 50.0 & 163944 \\
\hline 1251 & F & 61 & drowning & 3days & 41.4 & 135665 \\
\hline
\end{tabular}

PMI: Postmortem Interval, AMI: Acute Myocardial Infarction, *: Estimated age

Table1a: The list of decomposed cases.

*Corresponding author: Satomu Morita, Department of Legal Medicine, Shiga University of Medical Science, 3-7-2 Seta Tsukinowa-cho, Otsu City, Shiga, 520-2192, Japan, Tel: +81-77-548-2200; Fax: +81-77-548-2200; E-mail: m.satomu@gmail.com

Received May 01, 2013; Accepted May 21, 2013; Published May 27, 2013

Citation: Morita S, Furukawa S, Takaya A, Sakagushi I, Okunaga H, et al. (2013) Usability of Histological Assessment of Cerebellar Granule Cell Layer Regardless of Postmortem Interval. J Forensic Res 4: 180. doi:10.4172/2157-7145.1000180

Copyright: ( 2013 Morita S, et al. This is an open-access article distributed under the terms of the Creative Commons Attribution License, which permits unrestricted use, distribution, and reproduction in any medium, provided the original author and source are credited. 
Citation: Morita S, Furukawa S, Takaya A, Sakagushi I, Okunaga H, et al. (2013) Usability of Histological Assessment of Cerebellar Granule Cell Layer Regardless of Postmortem Interval. J Forensic Res 4: 180. doi:10.4172/2157-7145.1000180

\begin{tabular}{|c|c|c|c|c|c|c|}
\hline No. & Sex & Age & Cause of death & PMI & Percentage & Pixcel \\
\hline 1204 & M & 64 & drowning & $36 \mathrm{H}$ & 45.5 & 149105 \\
\hline 1205 & $\mathrm{~F}$ & 65 & brain contusion & $18 \mathrm{H}$ & 37.4 & 122552 \\
\hline 1215 & $\mathrm{M}$ & 44 & brain contusion & $34 \mathrm{H}$ & 45.3 & 148439 \\
\hline 1219 & $\mathrm{M}$ & 83 & drowning & $36 \mathrm{H}$ & 48.6 & 159163 \\
\hline 1222 & $\mathrm{~F}$ & 39 & hanging & $20 \mathrm{H}$ & 52.4 & 171565 \\
\hline 1226 & $\mathrm{M}$ & 38 & drowning & $36 \mathrm{H}$ & 47.4 & 155305 \\
\hline 1228 & $\mathrm{M}$ & 48 & AMI & $12 \mathrm{H}$ & 44.8 & 146709 \\
\hline 1268 & $\mathrm{~F}$ & 38 & AMI & $24 \mathrm{H}$ & 49.4 & 161935 \\
\hline 1278 & $\mathrm{~F}$ & 37 & choking & $18 \mathrm{H}$ & 37.8 & 123716 \\
\hline 1279 & $\mathrm{M}$ & 68 & brain contusion & $33 \mathrm{H}$ & 35.3 & 115671 \\
\hline 1280 & $\mathrm{M}$ & 20 & brain contusion & $10 \mathrm{H}$ & 50.5 & 165478 \\
\hline 1281 & $\mathrm{~F}$ & 74 & drowning & $24 \mathrm{H}$ & 47.2 & 154600 \\
\hline
\end{tabular}

AMI: Acute Myocardial Infarction, H: Hours

Table1b: The list of fresh cases.

The tissue sections of the cerebellum were obtained at autopsy. The tissue sections containing granular cell layer and dentate nucleus were fixed in $10 \%$ of formalin and embedded in paraffin within three days. The tissue sections with 3 microns were used for hematoxylin-eosin (HE) staining.

The evaluation of alteration of the granular cells was performed using Photoshop ${ }^{\text {Tw }}$ application. After taking photograph of the GCL stained by $\mathrm{HE}$ at microscopy level using Nikon $\mathrm{H} 550 \mathrm{~S}^{\mathrm{in}}$ system at magnification $\times 400$. Color of nucleuses of the granular cells was changed into gray and then the ratio of the number of pixels with gray color and other color was counted with Adobe Photoshop CS5 $5^{\mathrm{Ty}}$ (Adobe Systems ${ }^{\mathrm{n} x}$ ). The frequency of the remaining cells was indicated as percentage of the total number of pixel with gray color in the GCL. The area of remaining granular cells was indicated as the percentage of the GCL. When we counted number of pixels, we chose five visual fields of GCL, which looked equable and calculated average. In every case, whole pixels of one fields was 327,680 pixels (Figure 1).

Statistical analysis was performed with the $\mathrm{R}$ program, version 3.0.0 (the $\mathrm{R}$ project). To compare percentage between groups, the non-parametric Mann-Whitney $U$ test was used. A value of $p<0.05$ was considered statistically significant. To compare three groups, Bonferroni correction and Holm correction were performed.

\section{Results}

We could confirm granule cells in severe decomposed cases, and that look no obvious postmortem change in H.E. staining. For example the case, No.1251, was discovered by a fisherman, which floated in Lake Biwa, Shiga prefecture, in August that season was summer in Japan. The cause of death emerged from autopsy, drowning. We investigated blood and urine, we did not detect any drugs, but we did only caffeine, which was no relation to death. Histological appearance showed paler staining of eosin staining than fresh cases but no obvious postmortem change of form (Figure 2). We could see the pale pink of eosin staining in the GCL of many decomposed cases that was only feature we could observe.

The percentage of GCL of cerebellum of decomposed cases range $33.2 \%$ to $50.0 \%$, and the percentage of fresh cases $35.3 \%$ to $52.4 \%$. When we compared with these, we found no significant $(\mathrm{p}=0.1408$ $>0.05$ ) (Figure 3 ). We also compared about age and found no significant $(\mathrm{p}=0.55635>0.05)$.

The percentage of GCL showed different tendency by agonal situation, $\mathrm{CO}$ poisoning cases (group1), house fire cases (group2) and burning suicide cases (group3) (Table 2a). When we compared group1

and 2, we found statistical difference in spite of correction. However, we could not find statistical difference between group 2 and 3, 1 and 3 (Table 2b).

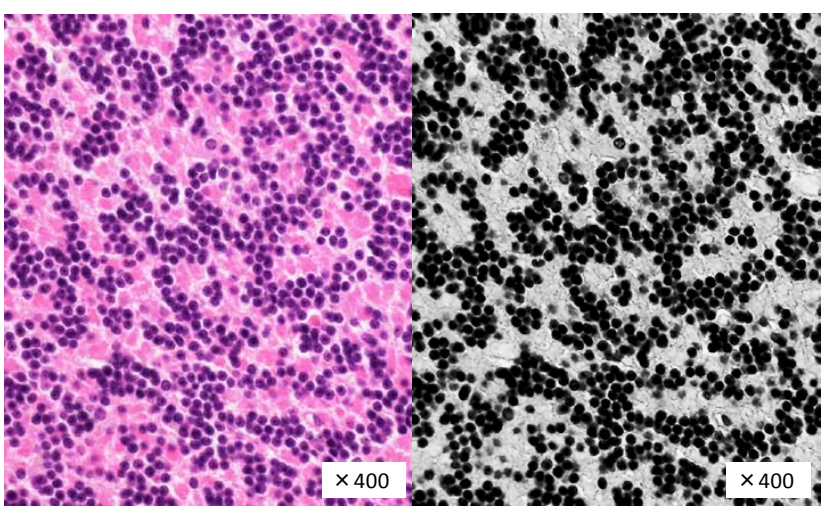

Figure 1: This is histological appearance of cerebellar GCL of No.1204, which was typical appearance with HE staining. We changed into gray and then counted the ratio of the number of pixels with gray color with Adobe Photoshop CS5.

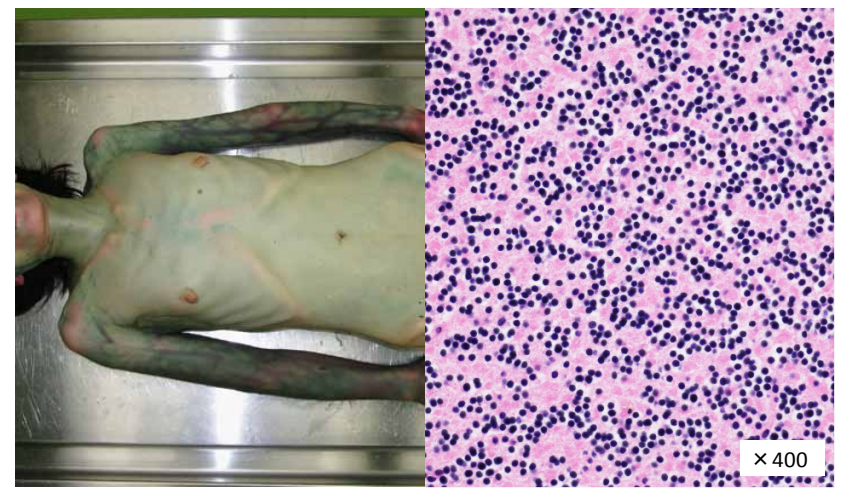

Figure 2: This is the one of decomposed case which was found in the lake in August. No obvious histological postmortem change was found in cerebellar GCL.

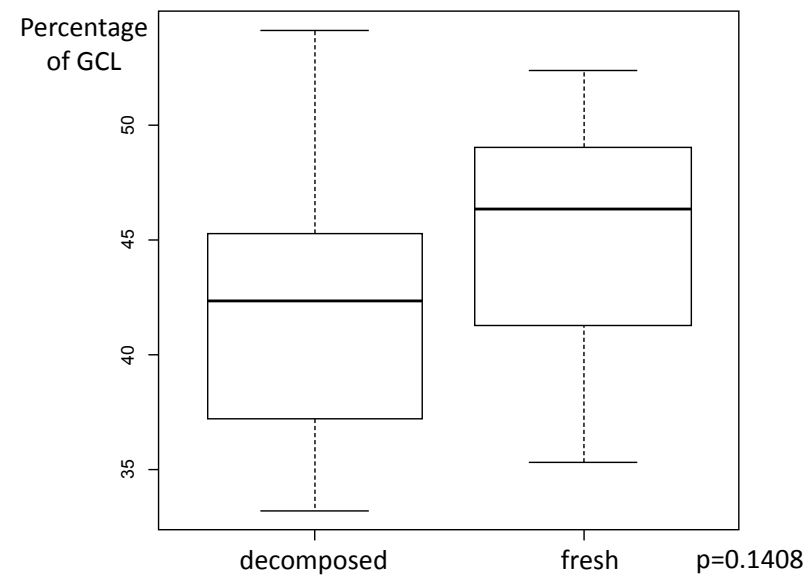

Figure 3: The box plots of composed cases and fresh cases showed no visual difference. 
Citation: Morita S, Furukawa S, Takaya A, Sakagushi I, Okunaga H, et al. (2013) Usability of Histological Assessment of Cerebellar Granule Cell Layer Regardless of Postmortem Interval. J Forensic Res 4: 180. doi:10.4172/2157-7145.1000180

Page 3 of 3

\section{Discussion}

GCL is very useful especially for apoptosis analysis. Some mechanisms of apoptosis were found in GCL [4]. It is noticed that global ischemia induce DNA fragmentation indicative of apoptosis of GCL [2]. In forensic science, it is noticed that apoptosis in CA1 and CA4 regions of hippocampus with regard to the causes of death, but some special immunostaining are needed for evaluation and it is difficult and uncertain to quantify [3]. Sheedy D et al. [5] performed histological analysis of cerebellar GCL with HE staining for a marker of brain tissue integrity in 2011, we may be able to evaluate brain damage during agonal phase and easily quantify with Photoshop ${ }^{\text {tw }}$ application.

Appearance of apoptosis during PMI, that was less than 24 hours, was investigated in skin, testis, thyroid, spleen and adrenal gland with Tunel staining [6,7]. In these report, apoptosis, which occurred during PMI, was not found. Though it was reported that various endogenous genes appeared in human postmortem tissues with time [8], gene must not be able to evolve histological change in postmortem tissues. In our analysis, no statistical difference between decomposed and fresh cases supports the hypothesis that apoptosis of cerebellar granule cells does not occur during PMI over 40 hours, neither.

We also evaluated cerebellar GCL of some cases of which agonal phase were different. In the situation of $\mathrm{CO}$ poisoning suicide, group 1 , the concentration of CO rise up slowly. On the other hand, in the situation of house fire, group 2, the victims inhale high concentration of $\mathrm{CO}$ or smoke including some kinds of chemical gas and died more quickly than group 1 . In group 3 , suicide by fire, the fire let them die in quite short time by the temperature of itself. We determined saturation of $\mathrm{COHb}$ in every case. It seems no relation between the percentage of GCL and saturation of $\mathrm{COHb}$.

We could only find the statistical difference of GCL percentage between group 1 and 2 that was because number of group 2 and 3 were very shortage. The comparison of the box plots suggested tendency of inverse proportion between the time to death and the percentage of GCL (Figure 4). In the future, accumulation and evaluation of many and various cases are desirable.

We could show usability of GCL regardless of postmortem interval and suggest some relations between GCL and agonal situation.

\begin{tabular}{|l|c|c|c|c|c|c|c|c|}
\hline & No. & Sex & Age & $\begin{array}{c}\text { Cause of } \\
\text { death }\end{array}$ & PMI & Percentage & Pixcel & CO \\
\hline Group 1 & 1240 & 39 & M & CO; charcoal & $20 \mathrm{H}$ & 29.7 & 97320 & 93.7 \\
\hline & 1241 & 41 & F & CO; charcoal & $30 \mathrm{H}$ & 27.7 & 90767 & 82.8 \\
\hline & 1274 & 46 & M & CO; charcoal & 4 days & 29.7 & 97320 & 8.4 \\
\hline & 1282 & 40 & M & CO; charcoal & $7-8$ days & $32.7 s$ & 107151 & 80 \\
\hline & 1283 & 38 & M & CO; charcoal & $7-8$ days & 21.4 & 70123 & 78.5 \\
\hline & 1301 & 26 & M & CO; charcoal & 6 days & 24.3 & 79626 & 87.1 \\
\hline & 1305 & 25 & F & CO; charcoal & 6 days & 26.8 & 87818 & 81.6 \\
\hline & 1310 & 55 & M & CO; charcoal & 3 days & 22.8 & 74711 & 84.1 \\
\hline & 1311 & 57 & F & CO; charcoal & 3 days & 33.7 & 110428 & 79.4 \\
\hline Group 2 & 1231 & 43 & F & house fire & $30 \mathrm{H}$ & 45.7 & 149749 & 79.5 \\
\hline & 1232 & 13 & F & house fire & $30-32 \mathrm{H}$ & 44.2 & 144834 & 89.5 \\
\hline & 1233 & 16 & F & house fire & $36 \mathrm{H}$ & 51.7 & 169410 & 83.5 \\
\hline Group 3 & 1214 & 62 & F & fire; suicide & $24 \mathrm{H}$ & 46 & 150732 & 0 \\
\hline & 1237 & 59 & M & fire; suicide & $12 \mathrm{H}$ & 65 & 212992 & 0 \\
\hline
\end{tabular}

PMI: Postmortem Interval, CO: Saturation of $\mathrm{COHb}, \mathrm{H}$ : Hours

Table 2a: List of different agonal phase cases.

\begin{tabular}{|c|c|c|c|}
\hline Group & p value & \multicolumn{2}{|c|}{ Correction } \\
\hline & & Bonferroni & Holm \\
\hline $1 \times 2$ & $0.016^{*}$ & $0.048^{*}$ & $0.048^{*}$ \\
\hline $1 \times 3$ & 0.0446 & 0.1338 & 0.0892 \\
\hline $2 \times 3$ & 0.4 & $1.2^{* *}$ & 0.4 \\
\hline
\end{tabular}

${ }^{*}: p<0.05,{ }^{* *}: p>1.0$

Table 2b: Statistical evaluation.

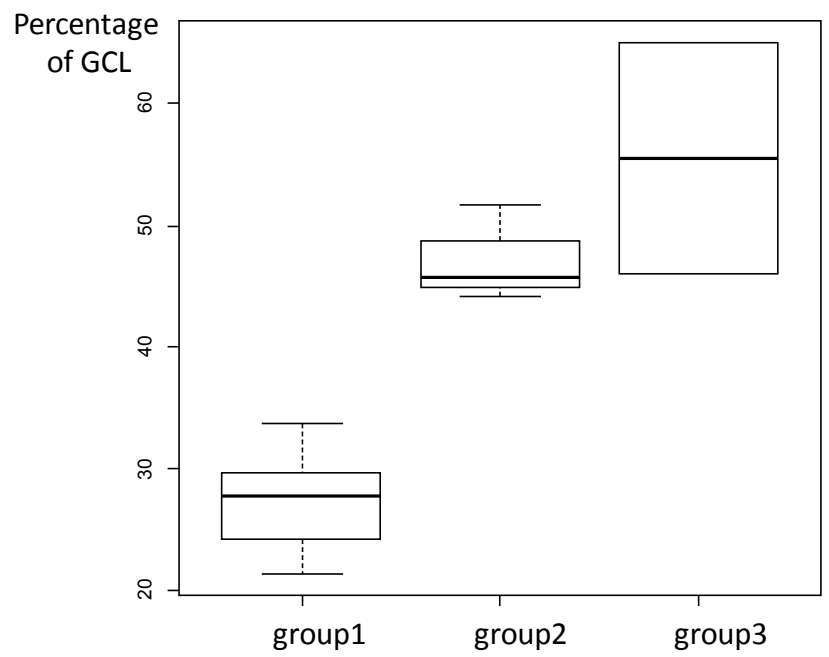

Figure 4: The box plots of three groups suggested the relation between the percentage of GCL and agonal situation.

\section{References}

1. Stan AD, Ghose S, Gao XM, Roberts RC, Lewis-Amezcua K, et al. (2006) Human postmortem tissue: What quality markers matter? Brain Res 1123: $1-11$.

2. Hara A, Yoshimi N, Hirose Y, Ino N, Tanaka T, et al.(1995) DNA fragmentation in granular cells of human cerebellum following global ischemia. Brain Res 697 : 247-250.

3. Michiue T, Quan L, Ishikawa T, Zhu BL, Maeda H (2009) Quantitative analysis of single-stranded DNA immunoreactivity as a marker of neuronal apoptosis in hippocampus with regard to the causes of death in medicolegal autopsy. Leg Med(Tokyo) 11:168-170.

4. Yamagishi S, Yamada M, Ishikawa Y, Matsumoto T, Ikeuchi T, et al. (2001) p38 mitogen-activated protein kinase regulates low potassium-induced c-Jun phosphorylation and apoptosis in cultured cerebellar granule neurons. J Biol Chem 276: 5129-5133.

5. Sheedy D, Harding A, Say M, Stevens J, Kril JJ (2012) Histological assessment of cerebellar granule cell layer in postmortem brain; a useful marker of tissue integrity? Cell Tissue Bank 13: 521-527.

6. Sakaguchi T, Jasani B, Knight B (1997) Identification of apoptotic cell nuclei in postmortem skin biopsies using the TUNEL reaction-effect of postmortem time interval. Acta Criminologiae et Medicinae Legalis Japonica 63: 39-43.

7. Kanetake J, Nata M, Adachi N, Hashiyada M, Ji G, et al. (1998) Effect of postmortem change on detection of apoptosis in rats. Nihon Hoigaku Zasshi 52: 144-148.

8. Zhang $\mathrm{H}$, Zhang $\mathrm{P}$, Ma KJ, Lv YH, Li W, et al. (2013) The selection of endogenous genes in human postmortem tissues. Sci Justice 53:115-120.

Citation: Morita S, Furukawa S, Takaya A, Sakagushi I, Okunaga H, et al (2013) Usability of Histological Assessment of Cerebellar Granule Cell Laye Regardless of Postmortem Interval. J Forensic Res 4: 180. doi:10.4172/21577145.1000180 